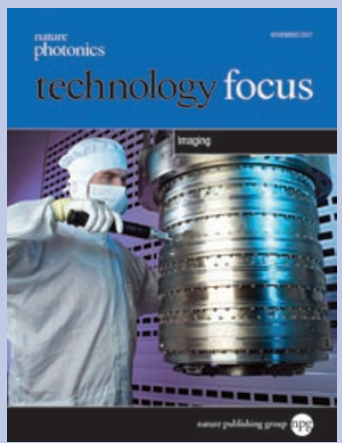

Cover image

A lens assembly used in deep ultraviolet lithography during chip manufacture.

Industry Perspective p629

EDITOR: OLIVER GRAYDON

ASSOCIATE EDITORS: AMBER JENKINS, DAVID GEVAUX, RACHEL PEI CHIN WON

PRODUCTION EDITORS: SIMON GERRARD, CHRIS GILLOCH

COPY EDITOR: ANNA DEMMING

ART EDITOR: KAREN MOORE

\title{
An alternative view
}

D

erhaps one of the most obvious and widespread applications of photonics is imaging, the topic of this Technology

Focus. For instance, many living creatures, ourselves included, rely on visible light and their sense of vision to navigate and find food. However, applications of imaging extend beyond the visible regime, especially for scientific and industrial purposes. The two Industry Perspective articles this month are a case a point.

The first, written by researchers from the German company Carl Zeiss SMT, takes a look at the future prospects for deep UV lithography - a form of high-resolution imaging used to define tiny features within semiconductor microchips during their fabrication. To support the production of ever faster computer chips that contain an ever increasing number of transistors, lithography is now having to project images of ever smaller feature sizes. As Michael Totzeck and coauthors explain on page 629 , the performance of deep UV lithography at a wavelength of $193 \mathrm{~nm}$ is now 'sub-subdiffraction-limited' and can define features as small as $40 \mathrm{~nm}$. What's more, thanks to the use of lowbirefringent optics and so-called doublepatterning techniques, it is possible that deep UV lithography could improve even further.

The second Industry Perspective is dedicated to an area of imaging at the other end of the electromagnetic spectrum thermal imaging, which relies on sensing radiation in the mid- and far-infrared. Thermal image sensors are usually composed of a focal-plane array consisting of pixels made from either a cooled semiconductor material or microbolometer elements. However, owing to limitations in the performance of such devices, alternative technologies are now being explored. One such idea is to use a photonic microring resonator as a pixel. On page 632, Michael Watts and colleagues from Sandia National Labs in Albuquerque, USA, explain the progress so far in realizing such microphotonic thermal sensors. The big benefit is the potential for sensitive operation without the need for cooling.

\section{MARKET ANALYSIS \\ 625 Indian promise Oliver Graydon}

RESEARCH HIGHLIGHTS 627 Advances in multicolour and multifocal imaging, and more

\section{INDUSTRY PERSPECTIVE} 629 Semiconductor fabrication: Pushing deep ultraviolet lithography to its limits Michael Totzeck, Wilhelm Ulrich, Aksel Göhnermeier and Winfried Kaiser

Optical resonators:

Microphotonic thermal imaging Michael R. Watts, Michael J. Shaw and Gregory N. Nielson

\section{BUSINESS NEWS}

Four companies join forces, a new centre for Bangalore, and more

\section{PRODUCT HIGHLIGHTS} 637 Imaging devices speed up, developments in the infrared, and more

\section{INTERVIEW}

